\title{
Factors associated with dietary supplement use in Saudi pregnant women
}

Hanan A Alfawaz ${ }^{1,3}$, Nasiruddin Khan ${ }^{2}$, Najlaa AlOteabi ${ }^{1}$, Syed D. Hussain ${ }^{3}$ and Nasser M. Al-Daghri ${ }^{3 *}$

\begin{abstract}
Background: The aim was to investigate the prevalence of dietary supplement use among pregnant Saudi women and its associations between various demographics.

Methods: In this cross-sectional study, a total of 137 pregnant women attending prenatal care from King Salman Hospital completed a self-administered questionnaire including socio-demographic characteristics, general awareness, attitude and behavior towards use of dietary supplements during pregnancy.

Results: Dietary supplement use among Saudi women in pregnancy was high (71.5\%) and was significantly associated with level of education $(p=0.005)$, family income $(p=0.039)$ and number of children $(p=0.007)$. No significant association was observed between neonatal health outcomes and dietary supplement use during pregnancy. In all participants, $81.6 \%$ believed that supplement use is important for nutritional status and more favorable neonatal outcomes. For the majority of participants, the primary source of information for dietary supplement use was a doctor's advice. The majority of the participants [65.7\% $(n=90)]$ responded that dietary supplement use is safe. Folic acid was found to be the most common type of dietary supplement used (95.9\%; $n=94)$; however, $53.1 \%(n=52)$ did not take folic acid supplements 3 months prior to pregnancy. Other common supplements used were iron, calcium and vitamin D (88.8, 81.6, and $41 \%$, respectively).
\end{abstract}

Conclusions: This study provided new information on dietary supplement use and its correlates in Saudi pregnant women. The prevalence of dietary supplement use was high in this group and was associated with sociodemographic and lifestyle characteristics.

Keywords: Dietary supplement, Attitude, Behavior, Socio-demographic, Saudi Arabia

\section{Plain English summary}

There is limited data available on the use of dietary supplement among pregnant Arab women. The present study aims to fill this gap. A total of 137 pregnant women from King Salman Hospital were recruited and completed a questionnaire. Results indicated that use of dietary supplements during pregnancy was high (71.5\%) and significantly associated with level of education, family income and number of children. No significant association was observed between infant health outcomes and dietary supplement use during pregnancy. The majority $(>80 \%)$ of participants acknowledge the importance of supplement use to compensate for increased metabolic demands of pregnancy. Doctor's

\footnotetext{
* Correspondence: aldaghri2011@gmail.com

${ }^{3}$ Biochemistry Department, College of Science, Prince Mutaib Chair for

Biomarkers of Osteoporosis, King Saud University, Riyadh 11451, Saudi Arabia Full list of author information is available at the end of the article
}

advice was the main source of information and $65.7 \%$ $(n=90)$ believed that dietary supplement are safe. Folic acid was the most common type of dietary supplement use $(95.9 \% ; n=94)$, followed by iron, calcium and vitamin D (88.8, 81.6, and $41 \%$, respectively). This study provided new information on the dietary supplement use and its correlates in Saudi pregnant women. The prevalence of dietary supplement use was high in this group and was significantly associated with differences in socio-demographic and lifestyle characteristics.

\section{Background}

The fast economic growth of Saudi Arabia in the last few decades has greatly affected the cultural diet and lifestyle of its general population. Energy-dense Western diets have replaced the traditional Saudi diet, which, in combination with a sedentary lifestyle, has led to an 
increased prevalence of non-communicable diseases such as obesity, type 2 diabetes mellitus and hypertension [1-7]. Furthermore, according to the World Health Organization (WHO), the most affected population from poor dietary habits and malnutrition are children, adolescents and women of reproductive age [8].

With the rising burden of diseases, Saudi Arabia is one of the largest pharmaceutical markets in the Arab region [9-11]. Furthermore, the well-established vitamin and supplement market in the country accounts for $4 \%$ of the total pharmaceutical market sales (US \$80 M) [12]. Many recent studies observed the lack of knowledge, especially in girls regarding micronutrients [13, 14] and supplement intake among pregnant Saudi women from various regions [15-17]. Moreover, a study performed by Gemeda Daba et al. has demonstrated a significant positive relationship between nutritional information and level of education among pregnant women [18]. However, there is scarcity of data regarding the prevalence of supplement use in Saudi pregnant women and the relationship with various socio-demographic factors, attitudes, behavior and awareness.

\section{Methods}

\section{Study population}

In this cross-sectional study, 200 Saudi pregnant women in their second or third trimester were recruited, out of whom 137 consented and completed the questionnaire. The participants were recruited from the obstetric clinics in King Salman Hospital, Riyadh, Saudi Arabia.

\section{Data collection and measurements}

A pilot study of 10 pregnant women was performed to confirm the reliability and validity of the questionnaire. Content and face validity were done by health professionals and physicians regarding the clarity in all questions. The questionnaire was then reviewed by experts in the related fields. Moreover, external reviewers provided their feedback and opinion in developing/improving the questionnaire to ensure reliability of the test. From the pilot study, the prevalence of supplement use was $75.0 \%$ among pregnant women. To achieve 95\% confidence intervals and $8 \%$ absolute error margin, 113 pregnant women were required. To overcome nonresponse 200 pregnant women were recruited.

Expert feedback and suggestions were incorporated in the final questionnaire. Furthermore, Cronbach's $\alpha$, an estimate of coefficient of reliability, $84 \%$ was measured for the questionnaire.

The participants were asked to complete the selfadministered questionnaire which was divided into four parts: (1) socio-demographic and lifestyle characteristics (less than 5000 Saudi Arabia riyals (SAR) was considered low income, between 5000 and 9999 SAR was considered average income 10,000-16,000 SAR was considered moderate income and more than 16,000 SAR was considered high income), (2) history of disease and prevalence of dietary supplement (DS) use, (3) reasons, duration, frequency and source of knowledge of dietary supplements, and (4) awareness and attitudes about supplement use and common types of dietary supplements used before and during pregnancy. The questionnaire also included the source of spending, and the circumstances surrounding use of dietary supplements.

\section{Data analysis}

Data was analyzed using the Statistical Package for Social Sciences (SPSS) 22.0 (SPSS Inc., Chicago, IL, USA). Data was presented as frequencies (\%). Pearson Chi-square test was used to examine differences between use of dietary supplements during pregnancy and body mass index (BMI), educational level, family income, occupation, number of children and neonatal health. All $p$-values were two-tailed, and $p$-values $<0.05$ were significant.

\section{Results}

Table 1 shows the socio-demographic/lifestyle characteristics of the participants $(n=137)$. The majority of the participants had a normal BMI $\left(<25 \mathrm{~kg} / \mathrm{m}^{2}\right)(N=52$; $38.2 \%)$, with average family income $(N=55 ; 40.1 \%)$, and most held college degrees $(N=93 ; 67.9 \%)$. The percentage of women employed and housewives were $(N=58$; $42.3 \%)$, and $(N=56 ; 40.9 \%)$, respectively.

The participant's history of disease and prevalence of dietary supplements use before and during pregnancy are presented in Table 2. Among all the participants, about $62.2 \%$ self-reported that they were vitamin D deficient.

The association between use of dietary supplements, BMI, educational level, family income, occupation and number of children are presented in Table 1 . The frequency of using dietary supplements during pregnancy was high and significantly associated with level of education $(p=0.005)$, family income $(p=0.039)$ and number of children $(p=0.007)$ as compared to non-users. There were no significant differences in the incidence of rickets, walking delays/appearance of teeth, weak or late growth, spina bifida, diabetes mellitus and allergies between those who are taking dietary supplement and those who don't (not shown in table). The duration of supplement use, reasons, frequency, and source of knowledge is shown in Table 3. Among all participants, $81.6 \%$ believed that their diet was insufficient for good health in pregnancy and use of supplements is important. The main reasons for the use of supplements in pregnancy was due to poor maternal nutritional status and neonatal requirements. The majority of participants 
Table 1 Use of Dietary Supplements during Pregnancy based on Sociodemographic/Lifestyle Characteristics

\begin{tabular}{|c|c|c|c|c|}
\hline \multirow[t]{2}{*}{ Parameters } & \multirow[t]{2}{*}{ N (\%) } & \multicolumn{2}{|c|}{ Dietary Supplement Use during Pregnancy } & \multirow[t]{2}{*}{$P$-values } \\
\hline & & Yes & No & \\
\hline BMI $\left(\mathrm{kg} / \mathrm{m}^{2}\right)$ Status & & & & 0.72 \\
\hline Underweight $(<19.5)$ & $7(5.1)$ & $6(6.2)$ & $1(7.7)$ & \\
\hline Normal (19.5-24.9) & $52(38.2)$ & $37(38.1)$ & $6(46.2)$ & \\
\hline Overweight (25-29.9) & $46(33.8)$ & $36(37.1)$ & $3(23.1)$ & \\
\hline Obese $(\geq 30)$ & $31(22.8)$ & 18 (18.6) & $3(23.1)$ & \\
\hline Educational Level & & & & 0.005 \\
\hline Intermediate or less & $6(4.4)$ & $4(4.1)$ & $2(15.4)$ & \\
\hline High School & $16(11.7)$ & $9(9.2)$ & $5(38.5)$ & \\
\hline Bachelor & $93(67.9)$ & $70(71.4)$ & $6(46.2)$ & \\
\hline Post Graduate & $22(16.1)$ & $15(15.3)$ & $0(0.0)$ & \\
\hline Family Income (SAR) & & & & 0.039 \\
\hline less than 5000 & $19(13.9)$ & $13(13.3)$ & $5(38.5)$ & \\
\hline 5000-9999 & $55(40.1)$ & $44(44.9)$ & $3(23.1)$ & \\
\hline $10,000-16,000$ & $35(25.5)$ & $24(24.5)$ & $1(7.7)$ & \\
\hline$>16,000$ & $28(20.4)$ & $17(17.3)$ & $4(30.8)$ & \\
\hline Occupation & & & & 0.79 \\
\hline Employee & $58(42.3)$ & $46(46.9)$ & $5(38.5)$ & \\
\hline Housewife & $56(40.9)$ & $38(38.8)$ & $6(46.2)$ & \\
\hline Student & $23(16.8)$ & $14(14.3)$ & $2(15.4)$ & \\
\hline Number of children & & & & 0.007 \\
\hline 2 and less & $78(56.9)$ & $61(62.2)$ & $3(23.1)$ & \\
\hline 3 to 5 & $46(33.6)$ & $30(30.6)$ & $7(53.8)$ & \\
\hline 6 to 8 & $12(8.8)$ & $7(7.1)$ & $2(15.4)$ & \\
\hline$>8$ & $1(0.7)$ & $0(0.0)$ & $1(7.7)$ & \\
\hline
\end{tabular}

Data presented as frequencies (valid \%)

described the source of information regarding dietary supplements was a doctor.

Table 4 shows the awareness and attitudes about dietary supplement use, most participants $65.7 \%(N=90)$ responded that they are safe to use. About 53.1\% $(N=52)$ did not take folic acid supplements 3 months prior to pregnancy. Folic acid was found to be the most common dietary supplements used among pregnant women $(95.9 \% ; N=94)$ followed by iron, calcium and vitamin D (88.8, 81.6 and $41 \%$, respectively).

\section{Discussion}

The present study is the first of its kind to demonstrate the high prevalence $(71.5 \%)$ of dietary supplement use among Saudi women in pregnancy. There was no significant association between health problems in babies and dietary supplement use in pregnancy. Number of children, monthly income and education level were significantly associated with supplement use as compared to non-users. There is a need to improve the level of awareness and attitudes about supplement use of common dietary supplements in pregnancy.

The prevalence of dietary supplement use in the general population has been reported in different parts of Saudi Arabia [19]. In addition, use of dietary supplements in pregnant Saudi women had been reported in several recent studies $[15,16,20,21]$. The high prevalence $(71.5 \%)$ of dietary supplement use in the present study reinforces these local findings. Furthermore, Aronsson and colleagues demonstrated that $92 \%$ of the 7326 women (from USA, Sweden, Finland, and Germany) were using one or more types of supplement during pregnancy [20]. Another study by Pouchieu and colleagues [21] showed a high proportion of pregnant women $(64.9 \%)$ in France used dietary supplements at least 3 days a week. The frequency of using dietary supplements during pregnancy was high and significantly associated with level of education, family income and number of children as compared to non-users. There are various studies from developed countries showing a positive association of dietary supplement use and socio- 
Table 2 History of Disease and Prevalence of Dietary Supplements

\begin{tabular}{ll}
\hline Participants History & N (\%) \\
\hline Do you any of the following health problems? & $34(29.3)$ \\
Anemia & $6(4.4)$ \\
Diabetes Mellitus & $13(9.7)$ \\
Dyslipidemia (High Cholesterol / High Triglycerides) & $8(6.1)$ \\
Hypertension & $7(5.3)$ \\
Osteoporosis & $14(10.7)$ \\
Thyroid Disorder & $74(62.2)$ \\
Vitamin D Deficiency & \\
Have you ever checked your vitamin status? & $76(57.6)$ \\
Yes & $56(42.4)$ \\
No & \\
Do you take supplements when you are pregnant? & $98(71.5)$ \\
Yes & $13(9.5)$ \\
No & $26(19.0)$ \\
Sometimes & \\
If yes, do you read the supplement's label before using? & $67(68.4)$ \\
Yes & $28(28.6)$ \\
No & $3(3.1)$ \\
Sometimes & \\
Yes you take supplements throughout pregnancy? & $66(67.3)$ \\
\hline
\end{tabular}

Data presented as frequencies (\%)

economic status during pregnancy [22-25]. The above mentioned studies $[20,21]$ also showed a direct correlation of dietary supplement use in pregnant women with higher income and educational status. The present study is consistent with these studies [20,21] showing a direct association between dietary supplement use with level of education and family income. Other studies have shown an inverse association between the number of children and use of dietary supplements in pregnancy [25-27]. However, Foote and colleague showed opposite results in that the number of children was not associated with dietary supplement use, in healthy women [28]. Pouchieu and colleagues demonstrated that women with children used less dietary supplements due to fewer physician consultations [21]. This finding was in accordance with the present result showing that women who had more children were used less dietary supplements as compared to those who have less children.

With regards to other micronutrients, vitamin D and iodine deficiencies have been associated with various fetal and maternal abnormalities $[29,30]$. The prevalence of vitamin D deficiency and insufficiency (50.0 and
Table 3 Perceptions and behavior related of dietary supplement use among Saudi women

\begin{tabular}{|c|c|}
\hline Survey Question & $\mathrm{N}(\%)$ \\
\hline \multicolumn{2}{|c|}{ Do you think your diet is sufficient and you don't need supplements? } \\
\hline Yes & $7(7.1)$ \\
\hline No & $80(81.6)$ \\
\hline Sometimes & $11(11.2)$ \\
\hline \multicolumn{2}{|c|}{ What are your reasons for using dietary supplements? ${ }^{a}$} \\
\hline Poor nutritional status & $71(72.4)$ \\
\hline Baby requirements exceed my usual diet & $72(73.5)$ \\
\hline I have nutritional deficiency & $68(69.4)$ \\
\hline \multicolumn{2}{|l|}{ How long have you been using supplements? } \\
\hline Less than 3 months & $30(30.6)$ \\
\hline 3 Months & $23(23.5)$ \\
\hline 6 Months & $28(28.6)$ \\
\hline 9 Months & $32(32.7)$ \\
\hline 12 Months & $7(7.1)$ \\
\hline More than a year & $14(14.3)$ \\
\hline \multicolumn{2}{|c|}{ Sources of information about vitamins and supplements ${ }^{a}$} \\
\hline Attending physician & $90(91.8)$ \\
\hline Friend's advice & $8(8.2)$ \\
\hline Internet & $14(14.3)$ \\
\hline Social Media & $7(7.1)$ \\
\hline \multicolumn{2}{|l|}{ Sources of Spending ${ }^{a}$} \\
\hline My expense & $54(55.1)$ \\
\hline Free & 31 (31.6) \\
\hline Insurance & $24(24.5)$ \\
\hline
\end{tabular}

Data presented as frequencies (\%); ${ }^{a}$ indicates questions with multiple responses

$43.8 \%$, respectively) has been reported among pregnant Saudi women with adequate vitamin D intake ( $\geq 600 \mathrm{IU} /$ day) among only $8.1 \%$ of pregnant women [14, 31, 32].

The most common type of dietary supplement used however in pregnant women was found to be folic acid followed by iron and calcium. Among participants, 44.9\% $(n=44)$ women took folic acid supplement 3 months before pregnancy, while $95.9 \%(n=94)$ took folic acid only during pregnancy. These results are not in accordance with other studies performed in Saudi Arabia $[15,16]$ and maybe due to the different levels of awareness among pregnant patients recruited to include educational level and the number of times the patient got pregnant. Despite discrepancy, the figures correspond to reports from the Netherlands [33] which showed the pre-conception intake of folic acid was up to $39 \%$.

It is known that the need for specific micronutrients such as folic acid increases during pregnancy [34]. For instance, $0.4 \mathrm{mg} /$ day of folic acid is recommended before 
Table 4 Awareness and Attitudes about Dietary Supplements used before and during Pregnancy

\begin{tabular}{llll}
\hline Survey Questions & Yes & No & Sometimes \\
\hline Do you think using dietary supplement is safe? & $90(65.7)$ & $18(13.1)$ & $29(21.2)$ \\
Do you take folic acid before pregnancy? & $44(44.9)$ & $52(53.1)$ & \\
Do you take the following dietary supplements during pregnancy? & & $16(16.3)$ & $2(2.0)$ \\
Calcium & $80(81.6)$ & $4(4.1)$ & $0(0)$ \\
Folic acid & $94(95.9)$ & $69(70.4)$ & $2(2.0)$ \\
lodine & $27(27.6)$ & $10(10.2)$ & $1(1.0)$ \\
Iron & $87(88.8)$ & $51(52.0)$ & $7(7.1)$ \\
Vitamin B Complex & $40(40.8)$ & $53(54.1)$ & $4(4.1)$ \\
Vitamin D & $41(41.8)$ & &
\end{tabular}

Data presented as frequencies (\%)

conception to minimize the risk of neural tube defects and megaloblastic anemia [35]. Recent studies showed that the prevalence and use of folic acid in Saudi women was between $6.8-9.7 \%$ based on its use during and before pregnancy [16]. A study performed by McWalter et al. showed that the prevalence of folic acid supplementation in pregnant Saudi women was $10 \%$ before 3 months and $3 \%(n=168)$ at 6 months of gestation [15].

The authors acknowledge some limitations of this study. First, the findings cannot be generalized due to small but adequate sample size, but because qualitative findings by nature are not generalizable, we do aim for transferability. Second, the list of supplements included was not comprehensive, thus possibly missing out other adjunct dietary influences. Lastly, age was not included in the questionnaire and hence further analysis on the influence of age on dietary supplement use is not included in the present study.

\section{Conclusion}

This study demonstrated new information on the use of different dietary supplements use during pregnancy as well as their relationship with various demographic factors and general awareness and attitude. Based on these results, the main reason behind using dietary supplements during or before pregnancy was to compensate for poor nutritional imbalance and neonatal requirements owing to increased metabolic demands of pregnancy. It appears necessary to increase awareness among pregnant women regarding the appropriate use of different dietary supplements before, after and during pregnancy. It is recommended to educate the general population through media and health professionals and work towards implementation of national recommendations of dietary supplement use during pregnancy.

\section{Abbreviations}

BMI: Body mass index; DS: Dietary supplements; SAR: Saudi Arabian Riyal;

SPSS: Statistical Package for Social Sciences; WHO: World Health Organization
Acknowledgements

The authors thank all the subjects who participated in this study.

Funding

The project was supported by Prince Mutaib Bin Abdullah Chair for Biomarkers of Osteoporosis, Deanship of Scientific Research, King Saud University.

Availability of data and materials

Data available upon request to the joint corresponding authors.

Authors' contributions

$\mathrm{HA}$ and NA contributed to the study design; subject selection and data collection were performed by NA, NK, SDH and NMA; data analyses was done by SDH; manuscript draft was prepared by NK and reviewed by HA, $\mathrm{SDH}$ and NMA. All authors read and approved the final manuscript.

Ethics approval and consent to participate

The study participants provided written informed consent for study participation that was conducted between April-May 2016. Approval for the study protocol was obtained from the Institutional Review Board of the College of Science, King Saud University.

Consent for publication

Not applicable.

Competing interests

The authors declare that they have no competing interests.

\section{Publisher's Note}

Springer Nature remains neutral with regard to jurisdictional claims in published maps and institutional affiliations.

\section{Author details}

${ }^{1}$ Department of Food Science and Nutrition, College of Food Science and Agriculture, King Saud University, Riyadh 11451, Saudi Arabia. ${ }^{2}$ Department of Food Science and Human Nutrition, Human Nutrition College of Applied Science, A'Sharqiyah University, $400 \mathrm{lbra}$, Oman. ${ }^{3}$ Biochemistry Department, College of Science, Prince Mutaib Chair for Biomarkers of Osteoporosis, King Saud University, Riyadh 11451, Saudi Arabia.

Received: 27 December 2016 Accepted: 28 July 2017

Published online: 29 August 2017

References

1. Al-Hazzaa HM. Physical activity, fitness and fatness among Saudi children and adolescents: implications for cardiovascular health. Saudi Med J. 2002; 23:144-50.

2. Musaiger $\mathrm{AO}$. Overweight and obesity in the eastern Mediterranean region: can we control it? East Mediterr Health J. 2004;10:789-93. 
3. Musaiger AO. Diet and prevention of coronary heart disease in the Arab Middle East countries. MedPrinc Pract. 2002;11:9-16.

4. Washi SA, Ageib MB. Poor diet quality and food habits are related to impaired nutritional status in 13- to 18-year-old adolescents in Jeddah. Nutr Res. 2010;30:527-34

5. Al-Daghri NM, Al-Attas OS, Alokail MS, Alkharfy KM, Yakout SM, Sabico SB, et al. Parent-offspring transmission of adipocytokine levels and their associations with metabolic traits. PLoS One. 2011;6(4):e18182.

6. Al-Nuaim AA, Al-Nakeeb Y, Lyons M, Al-Hazzaa HM, Nevill A, Collins P, et al. The prevalence of physical activity and sedentary behaviours relative to obesity among adolescents from Al-Ahsa, Saudi Arabia: rural versus urban variations. J Nutr Metab. 2012;2012:417589. http://dx.doi.org/10.1155/2012/417589

7. Al-Daghri NM, Al-Othman A, Alkharfy KM, Alokail MS, Khan N, Alfawaz HA, et al. Assessment of selected nutrients intake and adipocytokines profile among Saudi children and adults. Endocr J. 2012;59(12):1057-63.

8. WHO. Health of Adolescent Girls. Alexandria, Egypt: WHO Regional Office, 1994.

9. The Economist Intelligence Unit's healthcare (EIU) - Saudi Arabia: Healthcare and Pharmaceuticals Report August 2012.

10. Ministry of Health. Department of Statistics. Healthcare Indicators. http:// www.moh.gov.sa/en/Ministry/Statistics/Pages/healthinformatics.aspx. Accessed 24 July 2016.

11. Business Monitor International. Research and Markets. Saudi Arabia Pharmaceuticals and healthcare Report Q2 2009. http://researchandmarkets. net/reportinfo.asp?report id=992507. Accessed July 24, 2016.

12. NHP Consulting. Saudi Arabia. http://www.nhpconsulting.ca/services/world/ middle-east/saudi-arabia/. Accessed July 24, 2016.

13. Al-Saleh Y, Al-Daghri NM, Khan N, Alfawaz H, Al-Othman AM, Alokail MS, et al. Vitamin D status in Saudi school children based on knowledge. BMC Pediatr. 2015;15:53.

14. Al-Faris NA. High prevalence of vitamin D deficiency among pregnant Saudi women. Nutrients. 2016;8(2):77.

15. McWalter P, Al Shmassi A, Eldali A. Awareness and use of folic acid in a clinic-based Saudi pregnant population. Saudi J Med Med Sci. 2015;3(2): 141-5.

16. Al Rakaf MS, Kurdi AM, Ammari AN, Al Hashem AM, Shoukri MM, Garne E, et al. Patterns of folic acid use in pregnant Saudi women and prevalence of neural tube defects results from a nested case-control study. Prev Med Rep. 2015;2:572-6.

17. Bukhari AA, Bajouh OS, Aljehani MA, Alzahrani NJ, AlQahtani AM, Almrstani AMS. The awareness of folic acid supplements among women of childbearing age in king Abdulaziz university hospital, Jeedah - Saudi Arabia. J Nurs Care. 2016:5:346.

18. Daba G, Beyene F, Fekadu H, Garoma W. Assessment of knowledge of pregnant mothers on maternal nutrition and associated factors in Guto Gida Woreda, east Wollega zone. Ethiopia J Nutr Food Sci. 2013;3:6.

19. Aljaloud SO, Ibrahim SA. Use of dietary supplements among professional athletes in Saudi Arabia. J Nutr Metab. 2013;2013:245349. http://dx.doi.org/ 10.1155/2013/245349

20. Aronsson CA, Vehik K, Yang J, Uusitalo U, Hay K, Joslowski G, Riikonen A, Ballard L, Virtanen SM, Norris JM, TEDDY Study Group. Use of dietary supplements in pregnant women in relation to sociodemographic factors a report from the environmental determinants of diabetes in the young (TEDDY) study. Public Health Nutr. 2013;16(8):1390-402.

21. Pouchieu C, Levy R, Faure C, Andreeva VA, Galan P, Hercberg S, et al. Socioeconomic, lifestyle and dietary factors associated with dietary supplement use during pregnancy. PLoS One. 2013;8(8):e70733. doi:10.1371/ journal.pone.0070733.

22. Branum AM, Bailey $R$, Singer BJ. Dietary supplement use and Folate status during pregnancy in the United States. J Nutr. 2013;143(4):486-92.

23. Haugen M, Brantsaeter AL, Alexander J, Meltzer HM. Dietary supplements contribute substantially to the Total nutrient intake in pregnant Norwegian women. Ann Nutr Metab. 2008:52:272-80.

24. Woude PA, Walle HE, Berg LT. Periconceptional folic acid use: still room to improve. Birth Defects Res A Clin Mol Teratol. 2012;94:96-101.

25. Forster DA, Wills G, Denning A, Bolger M. The use of folic acid and othe vitamins before and during pregnancy in a group of women in Melbourne. Australia Midwifery. 2009;25(2):134-46.

26. McNally S, Bourke A. Periconceptional folic acid supplementation in a nationally representative sample of mothers. Ir Med J. 2012;105(7):236-8.
27. Arkkola T, Uusitalo U, Pietikainen M, Metsala J, Kronberg-Kippila C, Erkkola M, et al. Dietary intake and use of dietary supplements in relation to demographic variables among pregnant finnish women. Br J Nutr. 2006;96:913-20.

28. Foote JA, Murphy SP, Wilkens LR, Hankin JH, Henderson BE, Kolonel LN. Factors associated with dietary supplement use among healthy adults of five ethnicities: the multiethnic cohort study. Am J Epidemiol. 2003;157(10):888-97.

29. Li W, Green TJ, Innis SM, Barr SI, Whiting SJ, et al. Suboptimal vitamin D levels in pregnant women despite supplement use. Can J Public Health. 2011;102:308-12.

30. Stagnaro-Green A, Sullivan S, Pearce EN. lodine supplementation during pregnancy and lactation. JAMA. 2012;308:2463-4.

31. Kanan RM, Al Saleh YM, Fakhoury HM, Adham M, Aljaser S, Tamimi W. Yearround vitamin D deficiency among Saudi female out-patients. Public Health Nutr. 2013;16(3):544-8

32. Al-Mogbel ES. Vitamin D status among adult Saudi females visiting primary health care clinics. Int J Health Sci (Qassim). 2012;6(2):116-26.

33. EUROCAT folic acid working group: Special report: Prevention of neural tube defects by periconceptional folic acid supplementation in Europe. http://www.eurocat-network.eu/content/Special-Report-NTD-3rdEd-Part-I. pdf. Accessed July 24, 2016.

34. Blumfield ML, Hure AJ, Macdonald-Wicks L, Smith R, Collins CE. A systematic review and meta-analysis of micronutrient intakes during pregnancy in developed countries. Nutr Rev. 2013;71:118-32.

35. Candito M, Rivet R, Herbeth B, Boisson C, Rudigoz RC, et al. Nutritional and genetic determinants of vitamin $B$ and homocysteine metabolisms in neural tube defects: a multicenter case-control study. Am J Med Genet Part A. 2008;146A:1128-33.

\section{Submit your next manuscript to BioMed Central and we will help you at every step:}

- We accept pre-submission inquiries

- Our selector tool helps you to find the most relevant journal

- We provide round the clock customer support

- Convenient online submission

- Thorough peer review

- Inclusion in PubMed and all major indexing services

- Maximum visibility for your research

Submit your manuscript at www.biomedcentral.com/submit 